\title{
Anesthetic experience of a patient with cri du chat syndrome
}

\author{
Insoo Han, Yee-Suk Kim, and Sang-Wook Kim \\ Department of Anesthesiology and Pain Medicine, Bucheon St.Mary's Hospital, The Catholic University of Korea, Bucheon, Korea
}

Cri du chat syndrome (CdCS), first described by Lejune et al. in 1963, is a rare genetic disease resulting from a deletion of the short arm of chromosome 5. When planning an anesthesia for patients with CdCS, several problems, such as anatomical abnormalities of the airway, mental retardation, hypotonia, congenital heart disease and temperature maintenance, should be considered.

A 27-month-old female (body weight: $10 \mathrm{~kg}$ ) with CdCS was admitted for both medial rectus muscle resection surgeries because of both strabismus. She was born on the 38th gestational week by cesarean section, and birth weight was $1.9 \mathrm{~kg}$. Her DNA analysis, using phytohemagglutinin stimulated T-lymphocyte culture with GTG banding, and high resolution culture using ethidium bromide showed 46, XX, deletion of chromosome 5 13.2. The patient had mental retardation and characteristic morphology, like microcephaly and hypertelorism. A brain magnetic resonance imaging (MRI) checked at 14 months after birth showed a mild atrophy in cerebellar inferior vermis. We could not examine the patient's airway due to her young age and mental retardation. Preoperative laboratory examinations were within normal limits.

Preoperative vital signs were pulse rate $110 \mathrm{bpm}$, respiratory rate $20 / \mathrm{min}$, and body temperature $36.9^{\circ} \mathrm{C}$. Monitoring included electrocardiography, pulse oximetry, and capnography. Anesthetic induction was induced by intravenous administration of ketamine $30 \mathrm{mg}$ and glycopyrrolate $0.05 \mathrm{mg}$. Endotracheal intubation using portex endotracheal tube was facilitated by intravenous administration of rocuronium $4 \mathrm{mg}$. Intubation grade difficulty identified at laryngoscopy was grade 2 . Hydrocortisone succinate $20 \mathrm{mg}$ was administered intravenously after intubation. Maintenance of anesthesia was accomplished by sevoflurane, nitrous oxide and oxygen. The duration of surgery was $125 \mathrm{~min}$, and concluded uneventfully. After surgery, reverse of neuromuscular blockade was induced by pyridostigmine 1.8 $\mathrm{mg}$ and glycopyrrolate $0.07 \mathrm{mg}$. After identifying the adequate self-respiration, endotracheal tube was smoothly removed. She was sent to postanesthesia care unit and then to general ward uneventfully.

Although CdCS is known as a rare autosomal disorder, it is most common human chromosomal syndrome, with an incidence of $1: 37,000-1: 50,000$ live births [1]. The most important clinical features of CdCS are a high-pitched cat-like cry, distinct facial dismorphism, microcephaly, and severe psychomotor and mental retardation [2]. Atrophy of the brainstem mainly involving the pons, cerebellum, and median cerebellar white matter has been revealed by MRI [3].

Patients with CdCS have anatomic airway abnormalities, such as long curved floopy epiglottis and the narrow, diamondshaped appearance of the vocal cords. A combination of laryngeal abnormalities and micrognathia can make it difficult to perform an endotracheal intubation for general anesthesia. Awake laryngoscopy, before inducing anesthesia, could sometimes be helpful [4]. We could not evaluate the airway status because of her mental retardation and young age. However, endotracheal intubation was successfully accomplished.

It is recommended that all CdCS patients who are scheduled for general anesthesia should receive a thorough physical examination as a screen for congenital heart diseases, because variable congenital heart diseases are accompanied in 30\% of these patients [5]. Patients who have congenital heart diseases and are scheduled for invasive procedures are likely to cause bacteremia, thus should receive bacterial endocarditis prophylaxis [4]. Our

Corresponding author: Yee-Suk Kim, M.D., Department of Anesthesiology and Pain Medicine, Bucheon St.Mary's Hospital, 2, Sosa-dong, Wonmi-gu, Bucheon 420-717, Korea. Tel: 82-32-340-2158, Fax: 82-32-340-2255, E-mail: knabi_2000@yahoo.co.kr (c) This is an open-access article distributed under the terms of the Creative Commons Attribution Non-Commercial License (http:// creativecommons.org/licenses/by-nc/3.0/), which permits unrestricted non-commercial use, distribution, and reproduction in any medium, provided the original work is properly cited. 
patient had no congenital heart disease.

Vigilant monitoring and careful managements are essential to prevent intraoperative hypothermia in these patients. The use of warming blankets, a warm room temperature, heated and humidified inspired gases and warm intravenous fluids are helpful [4].
We report an case of uneventful perianesthetic management of a patient with CdCS, and suggest that careful consideration about the management of airway, coexisting congenital heart disease and temperature is needed.

\section{References}

1. Niebuhr E. The Cri du Chat syndrome. Epidemiology, cytogenetics and clinical features. Hum Genet 1978; 44: 227-75.

2. Cerruti Mainardi P. Cri du Chat syndrome. Orphanet J Rare Dis 2006; 1: 33.

3. Tamraz J, Rethore MO, Lejeune J, Outin C, Goepel R, Stievenart JL, et al. Brain morphology using MRI in Cri-du-Chat Syndrome. Report of seven cases with review of the literature. Ann Genet 1993; 36: 75-87.

4. Brislin RP, Stayer SA, Schwartz RE. Anaesthetic considerations for the patient with cri du chat syndrome. Paediatr Anaesth 1995; 5: 139-41.

5. Hills C, Moller JH, Finkelstein M, Lohr J, Schimmenti L. Cri du chat syndrome and congenital heart disease: a review of previously reported cases and presentation of an additional 21 cases from the Pediatric Cardiac Care Consortium. Pediatrics 2006; 117: e924-7. 